\title{
Discriminating Against Millennials in the Workplace Analysis on Age Discrimination Against Young Adults
}

\author{
Chanaz Gargouri, Carla Guaman \\ Saint Peter's University, Jersey City, New Jersey, USA
}

\begin{abstract}
Age discrimination is not only a problem for older professionals but also for young adults entering the workplace environment. Despite the fact that younger workers are more productive and less costly, they are typically the employees who are most likely to be laid-off. The problematic issue of age discrimination is a global matter; therefore an analysis on this public issue is a necessity. When addressing this issue, people tend to think that only older workers are being discriminated in the workplace. This paper focuses on understanding the perception of young adults between the ages of 18 and 29 about age discrimination in the workplace. A survey was shared through social media and 65 responses were retained. Data gathered were qualitatively analyzed from a sample population of young adult workers. The main focus of the paper is to understand the perception of young adults about age discrimination. Workable solutions were also suggested based on the survey results.
\end{abstract}

Keywords: millennials in the workplace, age discrimination, reverse ageism

Despite its perniciousness, age discrimination remains a form of discrimination that is unfortunately socially acceptable in the workplace (Bayl-Smith \& Griffin, 2014). Even with the regulations in relation to equal employment opportunity (EEO) in place, the Age Discrimination in Employment Act (ADEA) only protects employees who are above the age of 40. As it was clearly stated by the U.S. Equal Opportunity Employment Commission, "It is not illegal for an employer or other covered entity to favor an older worker over a younger one, even if both workers are age 40 or older" (EOEC, 2016). Discriminating against millennials, known as reverse ageism, is, perhaps, a new form of discrimination in the workplace that becomes salient to take actions in its regard.

Age discrimination is defined as the negative attitude toward individuals solely based on chronological age (Greenberg, Schimel, Martens, Solomon, \& Pyszcznyski, 2001; Tougas, Lagacé, de la Sablonnière, \& Kocum, 2004). The gap in the literature is that most researchers focused on older workers (DeArmond et al., 2006; McCann \& Giles, 2002) but little has been done on discrimination against millennials in the workplace. The focus of this paper is to understand the perception of young adults about age discrimination. Workable solutions were suggested based on the survey results.

Despite younger workers being more productive and less costly, they are typically the employees who are

Corresponding author: Chanaz Gargouri, ABD, MBA, professor, Department of Business Administration, Saint Peter's University, Jersey City, New Jersey, USA; research fields: millennials and the workplace, workplace performance, organizational psychology, social entrepreneurship, women entrepreneurship, leadership, workplace conflict.

Carla Guaman, senior student at Saint Peter's University, Jersey City, New Jersey, USA; research fields: age discrimination in the workplace, stereotypes about millennials, reverse ageism, experiences with securing employment, SurveyMonkey analysis. 
most likely to be laid-off (Indiviglio, 2009). This is due perhaps to companies trying to avoid age discrimination that specifically protects older workers in keeping their employment position much safer because of their seniority. Such amendment is creating a reverse age discrimination against young workers who are finding more difficulties in not only finding a job, but also maintaining their position in the job they find. Thus, the practice of younger workers being discriminated is actually worse or least to say equally important to the discrimination against older workers.

Practicing reverse age discrimination means ignoring the advantages of employing younger workers for the purpose to protect older employees in the company. Despite younger workers were proved to be more productive and more cost effective (Levenson, 2010), yet they are usually the first ones to be fired due to companies adapting a "first in, last out" policy for their employees. This policy is also making the nation's unemployment rate higher because companies have to ignore the job application of younger employees or use the contract amendment strategy as senior employees are tenured and still occupy their positions and get paid the highest wages. If protecting seniors is not the reason, then it would become questionable on why would employers ignore the fact that younger workers could bring more innovation and fresh thinking, leading to more growth in the long run for the company?

One must say that the younger employees have a lot of benefits but are being affected by companies wanting to not be accused of "age discrimination". These companies are inadvertently practicing "reverse age discrimination" in result, with the young workforce being at risk on finding or keeping their jobs. It is clear that younger workers need as much job safety as older employees with true equality of employees of all ages.

\section{Literature Review}

In their paper, Flowers, Jones, and Hogan (2010) defined millennial as Generation Y and Vanmeter, Grisaffe, Chonko, and Roberts (2013) expanded on the definition by indicating that millennials are those individuals who were born between the years 1980 through 2000. Other sources revealed a variation of the birth year (Karrh, 2013; Allison, 2013; Akkucuk \& Turan, 2016; Urbain, Gonzalez, \& Gall-Ely, 2013).

Generation Y is the future of business (Winograd \& Hais, 2014). Baby Boomers were a prominent part of the marketplace for a period of time, as these individuals accounted for a majority of the population resulting from the spike in births after World War II. Now, Baby Boomers are beginning to retire, and Generation Y is stepping in instead (Schawbel, 2013). Schawbel (2013) and the U.S. Department of Labor and Statistics, asserted on the importance of well knowing the millennials' workface as they will be accounting for $75 \%$ of the global workplace by 2025. A close look to the literature is revealing a limited research that was done on this subject. The assumption has always been that millennials' major problem is money and it would not be so hard to hire and retain them.

Departing from the assumption that "money is the best measure of success" (Gerzema \& D'Antonio, 2011, as cited in Winograd \& Hais, 2014, p. 6), Winograd and Hais (2014) indicated that the overwhelming majority of Generation $\mathrm{Y}$ do not hold this true. The authors discussed how this generation would rather make less money for a job they love versus making more money in a job they find uninteresting. Their findings are important to employee development. In order to truly make a company successful and fulfill this mission and vision, managers have to know their employees, and what motivates them. If a manager is from a different generation, such as the Baby Boomer or Generation X, then they might find it more difficult to relate to their employees and successfully integrate development into their management approach. 
Younger workers are falling victims to stereotypes by employers due to them being part of the "millennial age" (Bobbitt-Zeher, 2011). There are several key stereotypes that have led employers to generally avoid hiring a younger worker, making it harder for the young workforce to find employment (Allison, 2013). According to the literature, the "millennial age" is often looked as being entitled, hard to train, and uncommitted to their position of employment, when data are proving otherwise. More to add, younger workers are almost immediately discriminated when seeking employment because older generations have these stereotypes about the new generation of workers.

Younger workers are seen as entitled when the average young worker has large amount of student debts to pay off (Allison, 2013). As the author indicated, these workers have paid for degrees that were supposed to give them a decent salary upon graduation, but young workers are facing the reality that they may not even be able to make as much as previous generations of workers due to lack of employment opportunities (Shier, Graham, Goitam, \& Eisenstat, 2014).

Shier et al. (2014) also described that millennials are said to be hard to train when employees of past generations needed as much training in order to learn their job duties. Every work generation has faced a learning curve for job positions, yet the millennial stereotype makes employers see this in a much more negative light simply because of the age of the people seeking employment. The literature showed that younger workers were labeled by their employers as "job hoppers" because of their age and the likelihood that they are less likely to be committed to their position for long. In actuality, a study by Oxford Economics showed that millennials are committed to their position as much as past generations, as they also spend on average six months with the company much like the workers of the previous generations.

It is therefore clear from the literature review that younger workers are being unfairly discriminated when seeking employment. Data proved that the millennial age have the same shortcomings that all new employees have had over the generations of workers, yet somehow employers have made them stereotypes for hiring young employees. It is hard enough finding a job in today's world, but younger workers have to deal with these labels and stereotypes even before landing a job position.

\section{Causes of Millennial Discrimination}

Age discrimination is happening in almost every workplace (Bayl-Smith \& Griffin, 2014). As the literature showed, discrimination is a serious problem and it should not be tolerated anywhere. Companies assume that young employees are not qualified for the job because they are young (Shier et al., 2014). Shier et al. (2014) asserted that companies think that young employees do not know what they are doing and are not suitable for a full-time job. However, at the other end of the spectrum, age discrimination is affecting senior employees as well. Some companies think that senior employees are too old to be handling work and they also think that they are "past it". With all kinds of discriminations at wok, companies become less efficient and younger and older employees are having less flexibility if employment equal opportunity is not applied.

FT.com (2003) and Nolan (2015) discussed how the government should pass laws that prevent age discrimination. As they argued, it is an on-going problem now and it should not be going on if employees are qualified. People should not be forced to retire at a certain age and also young adults should be able to get a job if they are qualified for that job. Companies should judge employees based on their skills and work ethic, they should not be able to discriminate against age especially if that person is knowledgeable and can do the job well. Having a mandatory retirement age is considered discrimination. As the authors indicated, if someone is 70 
years old and is fully capable of doing the job efficiently, then that person should not be forced to retire. Also if someone is 70 years old and is capable of working full time, he might not be able to live off just with a pension. So financially, they need to keep working and as long as they could perform well, they should be able to continue working.

The authors indicated that the government should make age based rules illegal and consider two additional things: exclusions to allow mandatory retirement ages if companies can provide an adequate justification and default age of 70 , after which companies can on a case-by-case basis require employees to retire without providing justification. The company should be the one to decide if their employee is not qualified to work.

\section{Millennials Experiences in Securing Employment}

Shier et al. (2014) indicated that the issue of age discrimination against young adults is rapidly growing. The authors analyzed how the increasing nature of North America's labor market has created challenges for young adults in maintaining an employment. Shier et al. (2014) also provided a better understanding on this issue by actually showing a study done by one-to-one interviews and focus groups among 36 young adults between ages 18 and 29 done in a neighborhood called Jane-Finch in Toronto, Canada. As a result of this research, it suggested that the challenges can have a psychosocial impact on young adults who are discriminated based on their age. The authors concluded that age discrimination against young adults must be addressed through more substantive policy, regulatory and program based initiatives.

In their paper, Shier et al. (2014) claimed that globalization and technological advances, including an unregulated capitalist market have had an impact on the domestic labor market. Some of the factors that impact young adults in the labor market include the decline of middle-income occupations, the increase of challenges in securing full-time employment, and the separation of labor market between high skill high wage and low skill low wage. In North America, there has been an increase in part-time, temporary, and contract positions compared to full-time employment opportunities.

The authors also described how the lack of employment generally leads to deterioration of manifest and latent functions. For instance, lack of employment for young adults can lead to depression, low self-esteem, and anxiety. Also, unemployed young adults are likely to engage in destructive behaviors such as the excessive use of alcohol and tobacco, and even participating in criminal activity. Getting a stable job is very important for young adults to improve their life styles; therefore, there should be policies and programs discussing young adult unemployment.

\section{Research Questions}

Research Question 1: Have young adults from the New York metropolitan areas been discriminated in the workplace?

Research Question 2: How young adults from the New York metropolitan areas feel about being discriminated in the workplace?

\section{Methodology}

This study is an overt replicate of the study done by Shier et al. (2014). To better understand the labor market factors that impede young adult employment. The authors used one-to-one interviews to collect data from young adults between the ages of 18-29 in the Jane-Finch neighborhood in Toronto, Canada. The total 
was 36 participants, 25 males and 11 females. The mean age of the young adults is 22 years old. In this research, $15 \%$ of the respondents had experienced some post-secondary education, completed university or college. All the young adults in this research were identified as part of minority groups. The 29 reported being black, three Latin American, one South Asian, one Middle Eastern, one West Asian, and one East Asian. Although this research was done in Canada, the participants were very diverse. The interviews lasted about an hour in order to have a clear understanding on the experiences of the young adults interviewed in the labor market. Questions prompted respondents to describe their current and past experiences with employment and barriers that they experience when searching for employment opportunities. With regard to discrimination, respondents described negative experiences; the participants claimed that the employer's perception was that young adults would most likely be unable to meet the job expectations. As a result of those experiences of discrimination based on age, the respondents described implications for their own psychosocial functioning, such as internalizing and placing blame on themselves for their lack of labor market success. According to the interviews, all the young adults interviewed agreed that when they go for an interview, "they always say they will call you back; but they do not call you back", and this makes young adults have low perceptions that employers have potential employees based on their age. According to the research, employer perceptions of ability tend to be described by these respondents as having adequate previous experience and training in order to obtain a particular job.

One of the respondents described his experience when applying for a job as an administrative assistant in an office; the participant did not get the job since he did not have previous experience in that specific role. "Discrimination by employers around perceptions of individual ability continues to remain unregulated, allowing employers to openly discriminate based on perceived ability. Discrimination based on age is a factor identified by the respondents as a barrier to find employment". Another form of discrimination is age based which is another factor identified by respondents as a barrier to finding employment; perceived stereotypes of young adults as non-committal, irresponsible, and untrustworthy were identified by many respondents as impeding their successful labor market attachment. For instance, one respondent described: When I was 18 and 19 , employers treated me poorly because I was young. I had to work a job in the mall as a janitor. I got that job because of my appearance, because I looked young. If you look good for the job, you get it. Employers treated me different, based on my appearance or judged me because of my age. Because you are young, you are irresponsible. Or because you are young, you are good for this job, not for that job. I felt like a piece of meat because they judged me for my age... they do not give you a chance to prove yourself (female, 28 years old).

Age discrimination exists and a lot more young adults are being discriminated globally in the labor market today. According to the paper, knowing that age based discrimination by employers is prevalent, it is necessary to consider how the stereotypes emerge. The media plays a big role since they portray a negative image of young adults, usually centering on crime and violence, which has damaged young adult capabilities in securing employment. Due to the lack of employment for young adults, some of the respondents claimed that overcoming labor market barriers can be done by volunteering or taking any job in hopes of increasing choices in the labor market. The fact that many young adults do not have employment opportunities within the labor market can make them behave negatively - such as involvement in crime, therefore it is extremely important for the labor market to give young adults equal employment opportunities.

Based on the findings from the research done with various young adults from different backgrounds, it is imperative to look more deeply at the functions of the labor market in maintaining social inequality. This research seeks to understand if young adults from New York metropolitan areas feel the same way and find out 
whether reform of the hiring practices of the labor market in the New York metropolitan areas is serving a fundamentally cultural and societal purpose to better meet the needs and desires of the people as it is meant to serve. It is important to note that without adequate legislation and enforcement, many individuals - such as young adults who are constantly discriminated based on their age will continue to be victimized and marginalized, characterized by low-skill, low-pay, part-time, and temporary employment opportunities.

\section{Results and Suggestions}

Age discrimination involves treating someone less favorably because of his or her age. The ADEA only forbids age discrimination against people who are age 40 or older. It does not protect workers under the age of 40 , although some states do have laws that protect younger workers from age discrimination. It is not illegal for an employer or other covered entity to favor an older worker over a younger one, even if both workers are age 40 or older. The problematic issue of age discrimination is a global matter. It is stereotyping against individuals because of their age. When addressing this issue, people tend to think that only older people are being discriminated in the workplace. There are many cases of older people losing their jobs because of their age, but age discrimination is not only affecting older people but also young adults because of their lack of experience.

With this being said, a survey was developed to better understand how young adults feel about age discrimination. The population in this study was young adults between the ages of 18 and 29 from the New York metropolitan areas. The questions were developed so as to answer the research question: Have young adults from the New York metropolitan areas been discriminated in the workplace?

The survey consisted of nine questions and they were as follows: "How old are you?", "Are you a male or female?", "Are you currently enrolled as a student?", "What is your ethnicity?", "Are you currently employed?", "Have you ever been discriminated at work based on your age?", "As a young adult, do you feel like your coworkers tend to have stereotypes against you because of your lack of experience?", "Do you believe that age discrimination is a public issue in the workplace today?", and "What would you do to prevent age discrimination against young adults at work?".

The survey was shared through social media by the authors and had a total of 65 responses. The age of the people who took the survey ranged from 18 years old to 24 years old $(95.31 \%)$ and 25 to 29 years old (4.69\%). Twenty males completed the survey (30.77\%) and 45 females completed the survey (69.23\%). Fifty-three people who took the survey are currently employed (81.54\%) and the rest were unemployed (12.46\%). Out of the 65 people who took the survey, majority of them were enrolled as students and attended a four-year undergraduate college/university (67.69\%), and the rest were either in a full-time student in graduate school (4.62\%), part-time student at a four-year undergraduate college/university $(4.62 \%)$, full-time student at a two-year undergraduate college/university (7.69\%), part-time student at a two-year undergraduate college/university (1.54\%), at a high school or equivalent $(4.62 \%)$; or not currently enrolled as a student (9.23\%).

The ethnicity that stood out in the survey was Hispanic/Latino with a percentage of 44.62 , the rest included: white (29.23\%), black or African American (9.23\%), Asian/Pacific Islander (12.31\%), and other (4.62\%). Majority of the people who took the survey answered that they have never been discriminated at work based on their age $(69.23 \%)$, the rest responded yes (30.77\%). Majority of people who took the survey answered yes to feel that coworkers tend to have stereotypes against themselves because of their lack of experience $(60 \%)$, the rest answered no $(40 \%)$. There were a small percentage of people who did not believe 
that age discrimination was a public issue in the workplace today $(7.69 \%)$, the rest responded believing that age discrimination was a public issue in the workplace $(80 \%)$, and there was some who did not know if it was a public issue in the workplace today or not $(12.31 \%)$.

Some participants suggested that policies in relation to age discrimination within the workplace need to be ratified to prevent such issues. Others proposed to come up with seminars regarding age so employees could be trained more adequately. One of the solutions was to look closely at the skills sets of each employee so everyone could be placed where they deserve to be. Instead of looking at the age of an individual, the employer should look at the competency, relevant experience, and overall benefits that the employee will or is capable of bringing to the company since everyone has different attributes they can contribute. Another good solution to end this issue would be to educate young adults so that they can speak up about discrimination and be heard about it, and if that does not work out then to inform the corporation of the company they are working for. Some have even expressed that a lack of employment opportunities based on their age can lead to poverty, homelessness, criminal behavior, and substance abuse.

\section{Conclusions and Recommendations}

Age discrimination can be avoided and prevented in workplaces. First of all, this issue must be understood. Some people do not understand the definition that what age discrimination is. Employers must educate their workers or new employees of the policy, terms, and conditions of the job. Having a well-written policy will definitely include the definition of age discrimination and practical example to help the employees have a better understanding.

However, before educating employees, leaders must have viable knowledge as well to train others well. If leaders are not aware of this issue, they may hire a specialist to run a training program mandatory for everyone. In addition, leaders must create a positive working environment in the workplace so anyone who has an issue with discrimination especially age discrimination can be comfortable enough to speak up about it. Encouraging employees to always know that it is never acceptable to be age discriminated.

\section{References}

Akkucuk, U., \& Turan, C. (2016). Mobile use and online preferences of the millenials: A study in Yalova. Journal of Internet Banking and Commerce, 21(1), 1-11.

Allison, S. (2013). Employment and the millenials. Youth Studies Australia (Online), 32(2), 81-84.

Bayl-Smith, P. H., \& Griffin, B. (2014). Age discrimination in the workplace: Identifying as a late-career worker and its relationship with engagement and intended retirement age. Journal of Applied Social Psychology, 44(9), 588-599.

Bobbitt-Zeher, D. (2011). Gender discrimination at work: Connecting gender stereotypes, institutional policies, and gender composition of workplace. Gender and Society, 25(6), 764-786.

Deal, J. J., Altman, D. G., \& Rogelberg, S. G. (2010). Millennials at work: What we know and what we need to do (if anything). Journal of Business and Psychology, 25(2), 191-199.

DeArmond, S., Tye, M., Chen, P. Y., Krauss, A., Apryl Rogers, D., \& Sintek, E. (2006). Age and gender stereotypes: New challenges in a changing workplace and workforce. Journal of Applied Social Psychology, 36(9), 2184-2214.

Equal Opportunity Employment Commission (EOEC) (Ed.). (2016). Age discrimination. Retrieved March 25, 2017.

Espinoza, C. (2012). Millennial integration: Challenges millennials face in the workplace and what they can do about them. Doctoral dissertation. Antioch University: ProQuest Dissertations Publishing.

Ferri-Reed, J. (2014). Are millennial employees changing how managers manage? The Journal for Quality and Participation, $37(2), 15$.

Flowers, W., Jones, E., \& Hogan, R. L. (2010). Employee development approach for Generation Yers: A conceptual framework. Journal of Global Business Management, 6(1), 170-177. 
Friedlander, A. (2016). 5 tips for handling millennials in the workplace. BizWest, 35(13), 31.

FT.com. (2003). Age discrimination in the workplace. July 2, p. 1.

Greenberg, J., Schimel, J., Martens, A., Solomon, S., \& Pyszcznyski, T. (2001). Sympathy for the devil: Evidence that reminding whites of their mortality promotes more favorable reactions to white racists. Motivation and Emotion, 25(2), 113-133.

Indiviglio, D. (2009). Reverse-Ageism might be worse. Retrieved from http://www.theatlantic.com/business/archive/2009/05/ reverse-ageism-might-be-worse/18026/

Ito, M. (2011). Millennials' expectation of trust for supervisors and coworkers in the workplace. Doctoral dissertation. University of Kansas: ProQuest Dissertations Publishing.

Karrh, J. (2013). Marketing advice for millenials. Arkansas Business, 30(38), 27.

LaCore, E. (2015). Supporting millennials in the workplace. Strategic HR Review, 14(4), 155.

Levenson, A. R. (2010). Millennials and the world of work: An economist's perspective. Journal of Business and Psychology, 25(2), 257-264.

McCann, R., \& Giles, H. (2002). Ageism in the workplace: A communication perspective. In T. Nelson (Ed.), Ageism: Stereotyping and prejudice against older persons (pp. 163-199). Cambridge, MA: MIT Press.

Myers, K. K., \& Sadaghiani, K. (2010). Millennials in the workplace: A communication perspective on millennials' organizational relationships and performance. Journal of Business and Psychology, 25(2), 225-238.

Nolan, L. S. (2015). The roar of millennials: Retaining top talent in the workplace. Journal of Leadership, Accountability and Ethics, 12(5), 69.

Schawbel, D. (2013). Why you can't ignore millennials. Forbes.com, September 4.

Shier, M. L., Graham, J. R., Goitam, M., \& Eisenstat, M. (2014). Young adult experiences with securing employment: Perceptions of and experiences with employer discrimination and expectations hinder successful labor market attachment. Canadian Review of Social Policy/Revue Canadienne de Politique Sociale, 70, 48-63.

Tougas, F., Lagacé, M., de la Sablonnière, R., \& Kocum, L. (2004). A new approach to the link between identity and relative deprivation in the perspective of ageism and retirement. The International Journal of Aging and Human Development, 59(1), $1-23$.

Urbain, C., Gonzalez, C., \& Gall-Ely, M. L. (2013). What does the future hold for giving? An approach using the social representations of Generation Y. International Journal of Nonprofit \& Voluntary Sector Marketing, 18(3), 159-171.

Vanmeter, R. A., Grisaffe, D. B., Chonko, L. B., \& Roberts, J. A. (2013). Generation Y's ethical ideology and its potential workplace implications. Journal of Business Ethics, 117(1), 93-109.

Winograd, M., \& Hais, M. (2014). How millennials could upend Wall Street and corporate America. Brookings Institute. 